\title{
The Use Of The Collocation Algorithm For Estimating The Deformations Of Soil-Shell Objects Made Of Corrugated Sheets
}

https://doi.org/10.2478/sgem-2019-0048

received February 3, 2020; accepted May 4, 2020.

\begin{abstract}
The algorithm presented in this paper is intended for the analysis of deformations of shells in the construction phase of soil-shell objects when strain gauges and geodetic measurements are used. During the construction of such an object, large displacement values occur and the impact of axial forces on the displacement of a corrugated metal sheet is small. Internal forces (strain gauges), as well as the displacements of a selected circumferential band of the shell are determined directly from such observations.
\end{abstract}

The paper presents two examples of the analysis of large span shell structures of constructed objects, as well as the assessment of the effectiveness of the finite difference method (FDM) in beam schemes. Good deformation mapping was indicated using the collocation algorithm and the differential approach to the solution when there is a dense mesh and regular distribution of measuring points. In the analysed examples, a significant divergence between the support conditions adopted in the FEM calculation models and the actual static conditions in the objects was indicated. The collocation algorithm is especially designed for such situations. Collocation points in such a solution are used to consider a beam - separated from a structure and without boundary constraints, but with specific changes in curvature - as a reference system, which is determined from the geodetic measurements of two collocation points.

Keywords: Monitoring; soil-steel objects; corrugated sheets; collocation.

*Corresponding author: Czestaw Machelski, Department of Bridges and Railways, Faculty of Civil Engineering, Wroclaw University of Science and Technology, E-mail: czeslaw.machelski@pwr.edu.pl

\section{Introduction}

Soil-shell objects made of corrugated metal sheets are characterized, among others, by the fact that bearings are not used in them. ${ }^{[21]}$ Therefore, the support conditions of the shells are inherently unidentified, which means that the freedom of rotation is not fully preserved (hence, the moments), but at the same time, displacements are still possible. In practice, a design (calculation) scheme is strived to be met, that is, the obtaining of an articulated and non-sliding support in the building under construction. The paper considers the construction phase of the soil-steel structure, which is when the largest internal forces and displacements are created in the shell. However, the geometric diversity of this type of structure often requires an individual approach to the discussed problem. ${ }^{[25]}$ Additionally, the soil-structure interaction of a buried structure is affected by: the material, size and stiffness; by the construction method; by the type and placement of the backfill material; and by the external loading. ${ }^{[3,5,6,15]}$ Time-dependent analysis is described in [14]. Many works concern the problem of adjusting the soil-steel interaction. ${ }^{[1,25]}$

During the construction phase of a soil-shell structure, deformation of the shell is a random phenomenon. Soil impact resulting from different levels of ground ${ }^{[17,19,20,22]}$ on both sides of the shell, and also the compaction of backfill, are usually not symmetrical. ${ }^{[23]}$ Therefore, the function of the interaction of soil on the shell can be varied. Using the measuring base that is located on the shell gives the opportunity to observe the internal forces and displacements of the corrugated metal sheet of an object, ${ }^{[9,13]}$ as well as the interaction between the backfill and the shell. ${ }^{[10,11]}$

To monitor shell structures with the largest spans, strain gauges and surveying techniques are used simultaneously. ${ }^{[13]}$ In the case of measuring geodetic displacements, internal forces are determined as an additional result. In turn, internal forces, and hence additional displacements, are determined on the basis 
of measuring unit deformations. ${ }^{[9,11]}$. The paper shows the use of both measurement techniques in order to validate the collocation algorithm. ${ }^{[11,12]}$ The solution uses the finite difference method (FDM) ${ }^{[4,7,16,18]}$ when applied to beam systems. Therefore, an approximate solution is obtained from the FDM results, and thus, the differential coefficient $\eta$, which indicates a deviation from the exact FEM result, is used in the paper. The use of the collocation method ${ }^{[2,11]}$ with differential correction allows shell deformations in soil-shell structures, as well as in other construction models such as beam systems, to be correctly mapped.

The main advantage of the collocation algorithm and the differential solution is the ability to analyse a selected fragment of an object's structure, for example, one beam, without taking into account the boundary conditions in its contact with the rest of the structure. The loads of such a bar may not be precisely defined - they are coded in the bending moment diagram (in the change of the curvature), as is the case in the examples presented in the paper.

\section{Efficiency of the differential beam solution}

The paper uses the relation of bending moments in point $i$ that are calculated on the basis of the deflection line in the vicinity of this point using a differential approach ${ }^{[4,16]}$ with the form of:

$$
M_{i}(F D M)=-E \cdot \kappa_{i}=\frac{-E}{c^{2}}\left(w_{i-1}-2 w_{i}+w_{i+1}\right),
$$

where: $E I$ is the bending stiffness of the bar, while $c$ is the distance between points in the mesh of an element. Formula (1) is an equivalent to the differential moment dependence and the deflection function, as given below:

$$
M=-E I \frac{d^{2} w}{d x^{2}}
$$

Equation (2) is an exact approach to the relationship of moments and the deflection in a beam.

An approximate solution is obtained from Formula (1). Table 1 summarizes the results that were obtained from the calculation of three types of loads applied to a scheme of a simply supported beam. When it is assumed in the scheme that the beam is divided into two parts, $c=L / 2$ is obtained. The end points are the supports with numbers 0 and 4, and therefore, $w_{0}=w_{4}=0$. With such assumptions, a bending moment in middle point 2 is obtained from the following dependence

$$
M_{2}=\eta \cdot M_{2}(F D M)=\eta \frac{4 E I}{L^{2}} 2 w_{2} .
$$

In Formula (3), $M_{2}$ is an exact value obtained from Formula (2), while moment $M(\mathrm{FDM})$ is calculated from (1). From the proportions of these results, as in (3), the differential coefficients $\eta$ are determined and given in Table 1 .

Table 1 presents the results of calculations when there are four sections of mesh in the beam (as in the scheme), which is subjected to the previously analysed loads. In the case of calculations for middle point 2, as in (3), symmetry is assumed, and hence, $w_{1}=w_{3}$ and the following equation:

$$
M_{2}=\eta \cdot M_{2}(F D M)=\eta \frac{-16 E I}{L^{2}} 2\left(w_{1}-w_{2}\right) .
$$

When the bending moment in the intermediate point 1 is analysed, the following formula is used:

$$
M_{1}=\eta \cdot M_{1}(F D M)=\eta \frac{-16 E I}{L^{2}}\left(-2 w_{1}+w_{2}\right),
$$

This is due to the fact that $w_{0}=0$. The values of the differential coefficients given in the table show that they depend on the load case, and therefore, on the shape of the bending moment diagram and the density of the beam division mesh into sections $c$.

Figure 1 shows an example of a simply supported beam loaded with intermittent distributed force $q$ along length $b$. The division of the beam into sections with lengths $L=6 b=18 c$ was assumed in the calculations. With these assumptions, the following deflection functions are obtained:

- beam section $0<x<b$ with the load

$w=\frac{3 q c^{2} b^{2}}{2 E I} \frac{x}{L}\left\{17-18\left[\left(\frac{x}{L}\right)^{3}+\left(\frac{L-x}{L}\right)^{3}\right]+\left(3 \frac{L-x}{L}-2\right)^{2}\right\}$,

- middle section of the beam $b<x<2 b$ without the load

$$
w=\frac{3 q c^{2} b^{2}}{2 E I} \frac{x}{L}\left\{17-18\left[\left(\frac{x}{L}\right)^{3}+\left(\frac{L-x}{L}\right)^{3}\right]\right\} .
$$


Table 1: List of the analysed static quantities.

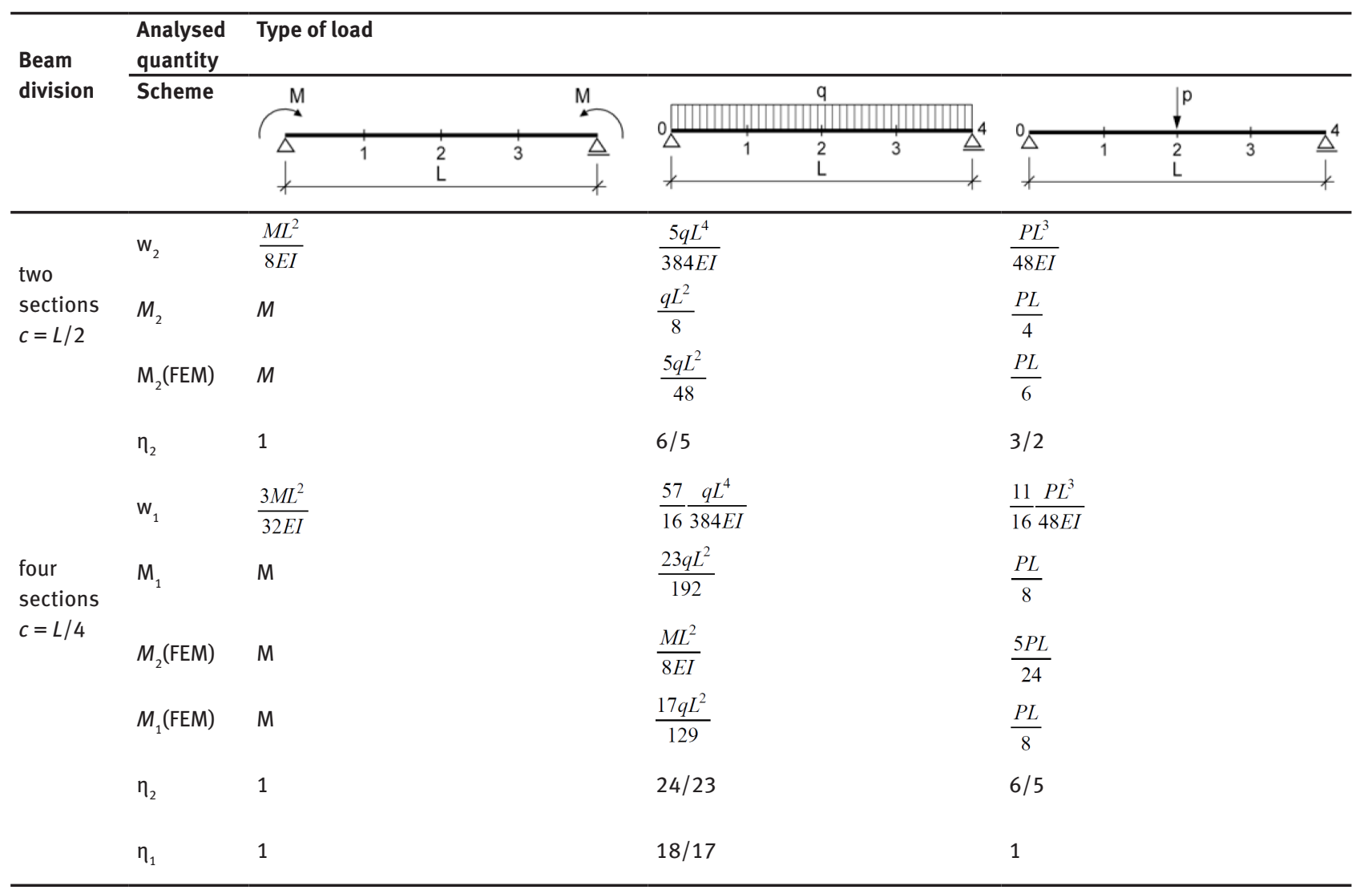

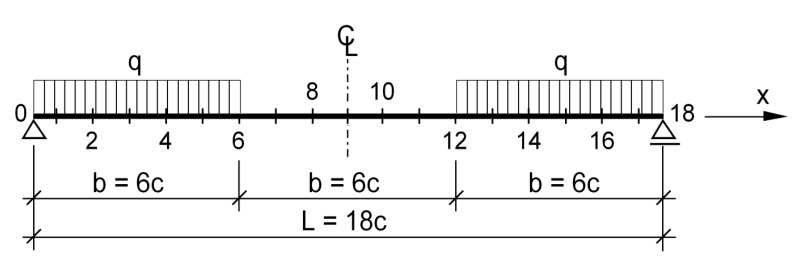

Figure 1: Static scheme of an analysed beam system.

Bending moments in section $0<x<b$ change according to the following dependence:

$$
M=\frac{q L^{2}}{6}\left[2 \frac{x}{L}-3\left(\frac{x}{L}\right)^{2}\right],
$$

while in the central part of the beam, there is a constant value of:

$$
M=\frac{q L^{2}}{18} .
$$

The bending moments that are specified in Formulas (8) and (9), according to Equation (1), are associated with deflections according to the following relation:

$$
M_{i}=\eta \cdot M_{i}(F E M)=\eta \frac{-E I}{c^{2}}\left(w_{i-1}-2 w_{i}+w_{i+1}\right)
$$

In this example, according to the results in Table 1, there is a constant value of $\eta=1$ in the middle of the beam. In the end section $0<x<b$, the differential coefficients assume small values of $\eta_{1}=1.0154 ; \eta_{2}=1.0084 \ldots \eta_{6}=1.0023$. Therefore, the values of coefficients indicate a technically correct estimation of bending moments in the entire area of the analysed beam (without taking into account $\eta$ ).

\section{Differential solution of the arch}

Figure 2a shows a scheme of an arch with a shape of a half circle that has radius $R$. The bending stiffness of arch $E I$, and the compressive stiffness $E A$, are constant along its length. The symmetrical load of the distributed force $p(s)$ with a radial direction also causes symmetrical deformation of the shell, which is determined by the function $r(\mathrm{~s})$. In the arch, it is determined by the maximum displacements: vertical $r_{\mathrm{k}}$ - the uplift of the crown, and horizontal $r_{\mathrm{o}}$ - the narrowing of a side wall. Figure $2 \mathrm{~b}$ shows a symmetrical, in relation to the crown, distribution 

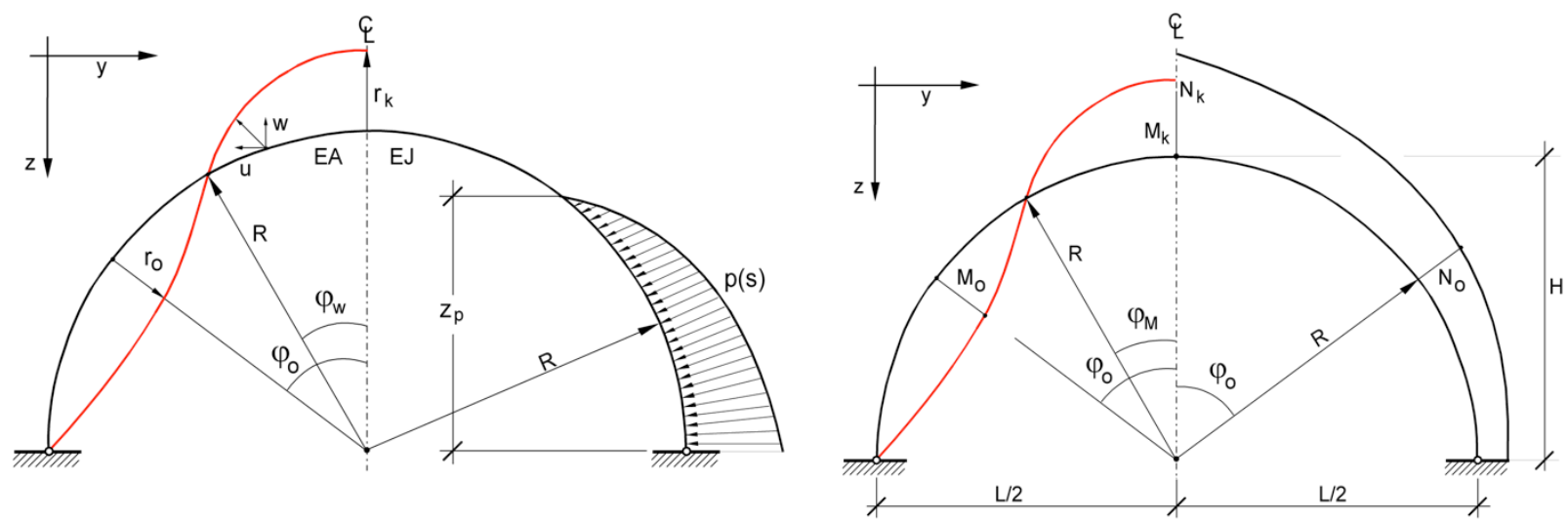

Figure 2: Diagram of the impact of filling, and also the deformation of the circumferential layers of the shell.

of internal forces along the length of the arch. In general, the effect on $\operatorname{arch} p(\mathrm{~s})$ is associated with the distribution of axial force $N(\mathrm{~s})$ and the distribution of bending moment $M(\mathrm{~s})$ along the arch according to the following equation:

$$
p(s)=\frac{N}{R}+\frac{d^{2} M}{d s^{2}} .
$$

In the analysed case of the arch, displacements depend on the internal forces included in the Mohr equation, which has the form of:

$$
r=\int \frac{M \cdot M_{r}}{E I} d s+\int \frac{N \cdot N_{r}}{E A} d s=\int \kappa \cdot M_{r} \cdot d s+\int \varepsilon \cdot N_{r} \cdot d s
$$

In this formula, $M(\mathrm{~s})$ and $N(\mathrm{~s})$ are the internal forces resulting from the load $p(\mathrm{~s})$, while $M_{\mathrm{r}}(\mathrm{s})$ and $N_{\mathrm{r}}(\mathrm{s})$ are tracking functions of displacements with a radial direction $r$. The paper uses the assumption of a negligible influence of axial forces. This is justified in the case of considering the loads located in the lower part of the arch, as in Figure 2a.

The integral approach ${ }^{[9]}$ is replaced in the paper by a differential relation, as in (10), in the form:

$$
M_{i}=-E I\left(\frac{d^{2} r}{d s^{2}}+\frac{r}{R^{2}}\right)=\eta \cdot M_{i}(F D M)=\eta \frac{-E I}{c^{2}}\left[r_{i-1}-2 r_{i}+\left(\frac{c}{R}\right)^{2} r_{i}+r_{i+1}\right] .
$$

In this case, $c$ is the length of the arch - a segment of a circle with a radius $R$ formed between the points of the regular mesh of the division into elements. In the analysed example, load $p$ is a radial hydrostatic interaction.

Figure 3 presents diagrams of the analysed quantities that were obtained from the FEM solution. The following numbering of points was adopted: 0 - a support, and 15 - a crown, and therefore, a quarter of the circle was divided into 15 segments. From the comparison of bending moments $M(\mathrm{~s})$ and $M_{\mathrm{MRS}}(\mathrm{s})$, and with the use of displacements $r(\mathrm{~s})$, as in Equation (13), the function $\eta(\mathrm{s})$ that is shown in Figure 4 is obtained. Therefore, in order to obtain the correct bending moments (FEM) from the differential Equation (13), it is necessary to correct the displacements with the value of differential coefficients.

FEM results in the form of bending moments and displacements - treated as exact values - were used in the previously presented calculation examples. On this basis, the differential coefficients $\eta$ were determined for various construction and load schemes. The results from the examination of objects, the bending moments obtained from strain gauges, and the displacements obtained from geodetic readings are used in the case of the analyses considered in the paper.

\section{A collocation algorithm used for a shell made of a corrugated metal sheet}

The testing of soil-shell objects made of corrugated sheets, as in Figure 5a, involves the use of strain gauges in the points of the scheme given in Figure 5b. From these measurements, the curvature change is obtained while using the principle of plane cross-sections:

$$
-\kappa=\frac{-M}{E}=\frac{\varepsilon_{g}-\varepsilon_{D}}{f} .
$$




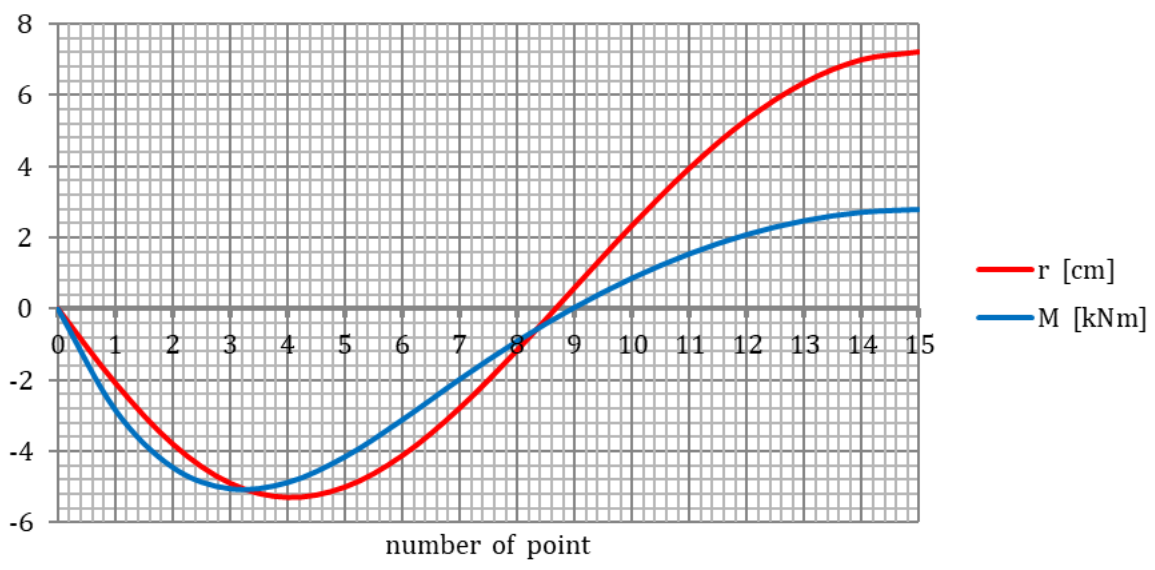

Figure 3: The diagrams of the bending moments and displacements calculated using the FEM model.

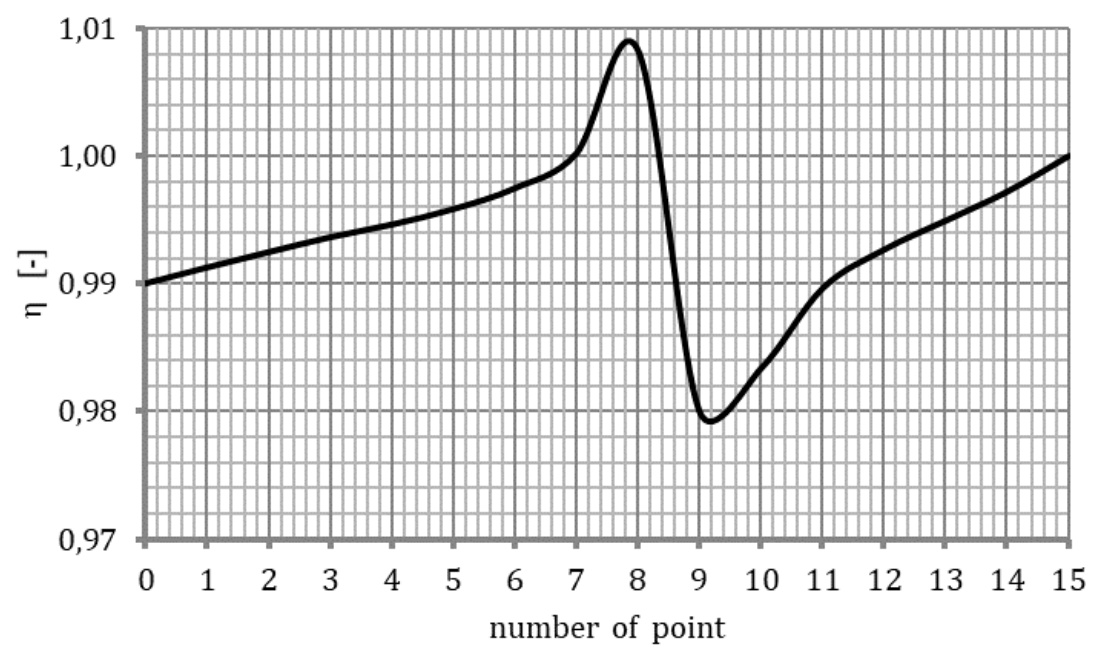

Figure 4: Distribution of differential coefficients along the length of the arch.

and the deformation in the cross-sectional axis of the circumferential beam:

$$
\varepsilon=\frac{1}{2 f}\left[(f+t) \varepsilon_{g}+(f-t) \varepsilon_{D}\right] .
$$

These quantities appear in Mohr Equation (12), which is used to calculate displacements $r .{ }^{[10,24]}$ In the paper, however, they are used to calculate the function of displacements $r$ from relationship (13), as in the given formula:

$$
\frac{-\kappa_{i}}{\eta} c^{2}=r_{i-1}-2 r_{i}+\left(\frac{c}{R}\right)^{2} r_{i}+r_{i+1}
$$

Calculations of the displacements start from the collocation point and the assumption of the displacement $r_{\mathrm{i}}$ of that point. Based on the initially adopted value $r_{\mathrm{i}+1}$ (adjacent point), the displacement in the adjacent point $(i-1)$ is also obtained from:

$$
r_{i-1}=\frac{\kappa}{\eta} c^{2}+\left[2 r_{i}-\left(\frac{c}{R}\right)^{2}\right] r_{i}-r_{i+1} .
$$

Because the initially adopted value $r_{i+1}$ is arbitrary, the appropriate displacement in the second collocation point is not obtained. In order to achieve the compatibility of results in this point, angular transformation is necessary. This transformation is also used to determine the 
a)

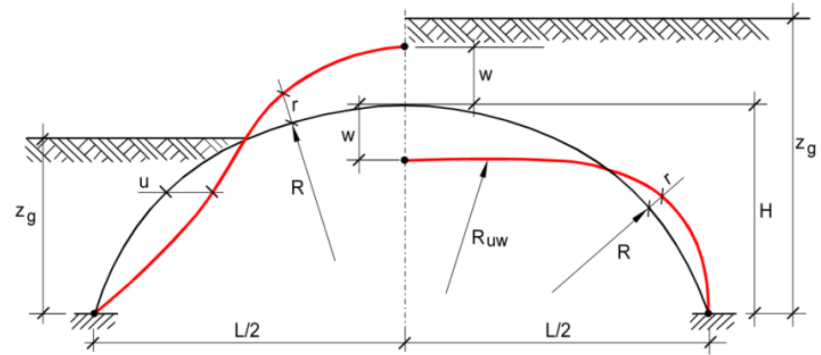

b)

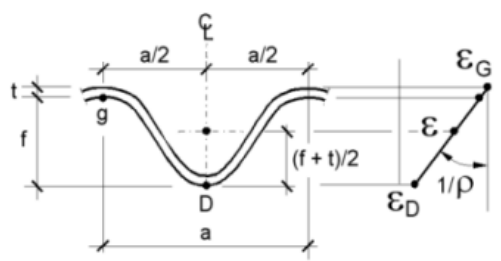

Figure 5: Geometry of the circumferential band of the shell: a) deformation of the shell, b) distribution of the deformations in the crosssection of the shell that is evaluated.

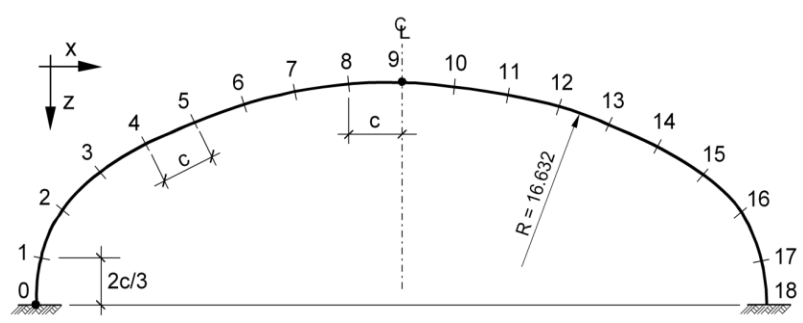

Figure 6: Scheme of the circumferential band of the shell with the collocation points.

differential coefficient $\eta$ in Formula (17). Therefore, the displacements at the collocation points obtained from Formula (17) are accurate, and at the remaining points of the mesh, they can be considered as close to the correct values. If these results are similar, it can be seen that both displacement functions - from the geodetic measurements (including collocation ones), and that obtained from (17) - are adjusted.

The difference between integral algorithm (12) and differential algorithm (17) is basic. In (12), there are displacement tracking functions $M_{\mathrm{r}}(\mathrm{s})$ and $N_{\mathrm{r}}(\mathrm{s})$, in which the considered static scheme is treated as a design assumption. The construction of the support of the built shells shows that it is not an articulated and nonsliding connection, which is visible in the examples of measurement results carried out on objects. However, in Formula (17), there are no boundary conditions for the beam. They are replaced by displacements at two collocation points, as in Figure 6. Their position (any) is determined on the basis of, for example, geodetic measurements. It is important that these points are characteristic for the deformation of the beam, for example, the displacement of the crown and the sidewall of the soil-shell structure, as in Figure 6.

The algorithm given in the paper is intended for the analysis of the deformation of a shell during the construction phase of a soil-shell object when using strain gauges and geodetic measurements. In such a case, there are large displacement values, and the influence of axial forces on the strain is small. Such measurements are performed when monitoring a facility during the laying of a backfill, and also during the tracking of changes in the initial phase of the exploitation. ${ }^{[13]}$

\section{The shell of a large object in Ostroda}

The analysed example of the object in Ostroda ${ }^{[9]}$ is the largest structure in Poland. It has the geometric characteristics of a shell with the shape of circle fragments, and a radius of curvature $R=16.632 \mathrm{~m}$ (and corner $R_{\mathrm{n}}=6.12$ m), span $L=25,724 \mathrm{~m}$, and shell height $H=9.11 \mathrm{~m}$. The geometry of the corrugated metal sheet is expressed by its technical designation UC $500 \times 237 \times 9.65$. It is the Ultra Cor type and has parameters: $a=500 \mathrm{~mm}$ - wave length, $f=237 \mathrm{~mm}$ - wave height, $t=9.65 \mathrm{~mm}$ - sheet thickness. During the construction and monitoring of the object, strain gauge measurements were taken in the points given in Figure 6, and geodetic measurements in the points that are distant by $2 c$.

The results of the analyses given in the paper relate to the construction phase, that is, laying of the backfill, where $z_{\mathrm{g}}$ determines its thickness, as in Figure 5a. Figure 7 shows a comparison of the radial displacement results obtained from geodetic measurements $r(\mathrm{uw})$ and those calculated using Formula (17) - as $r$ (FDM), where $z_{g}=$ $H=9.2 \mathrm{~m}$. They refer to the bending moments diagram, which is associated with the change of curvature, as in Formula (14), when $E I=9.92 \mathrm{MNm}^{2}$ and the bands have a width of $a=0.5 \mathrm{~m}$. After the angular transformation used in Equation (17) for the selected backfill thicknesses $z_{\mathrm{g}}[\mathrm{m}]$ 

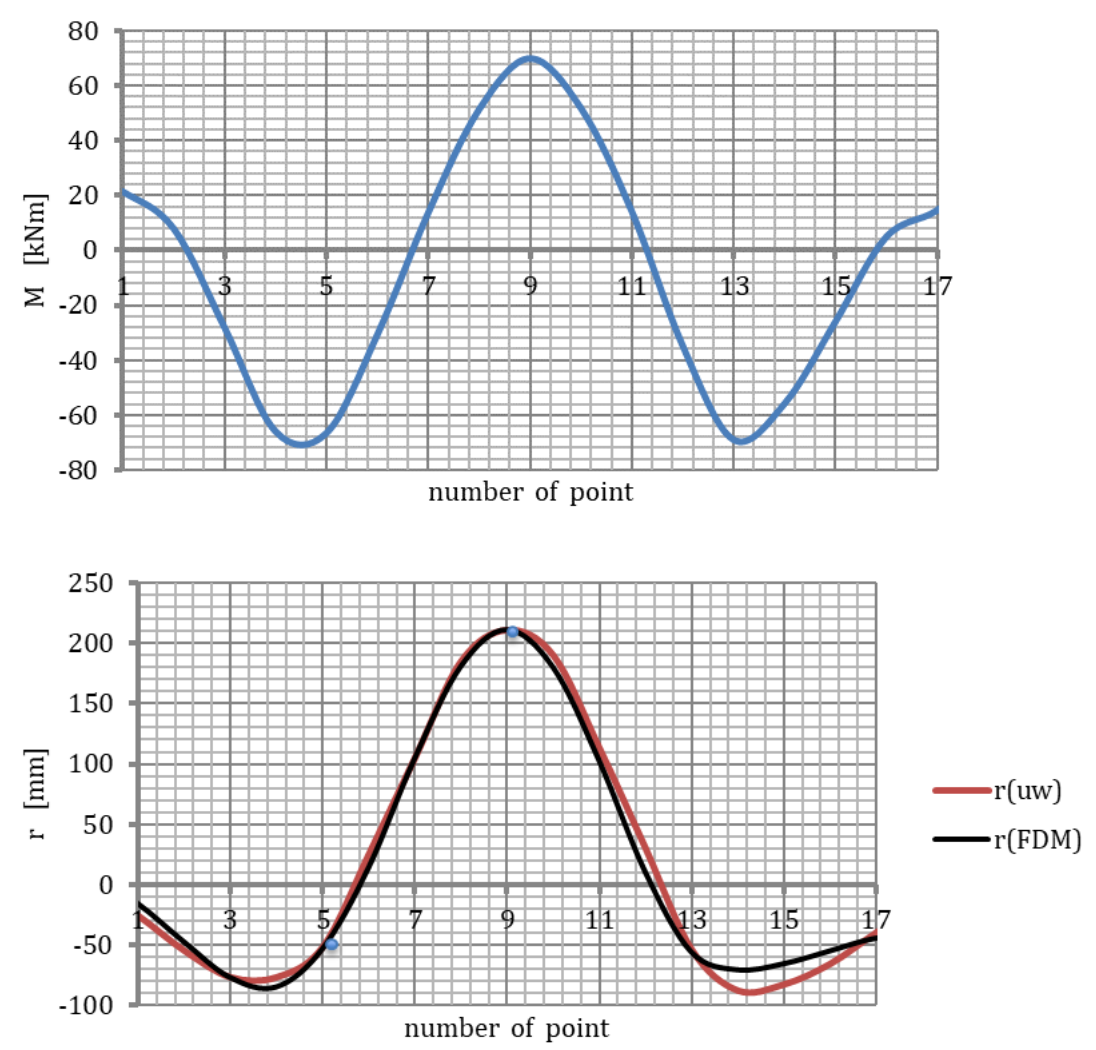

Figure 7: Bending moments and radial displacements in the circumferential band of the shell when $\mathrm{z}_{\mathrm{g}}=\mathrm{H}$.

(given in brackets), the following differential coefficients were obtained:

$$
\begin{gathered}
\eta(6.3)=4 / 7 ; \quad \eta(7.5)=4 / 7 ; \quad \eta(9.2)=5 / 9 ; \quad \eta(10.4)= \\
20 / 41 .
\end{gathered}
$$

These values (mean values according to Figure 6) take into account the change in soil interaction on the shell at various backfill levels (when $z_{\mathrm{g}}=H$, the backfill reaches the level of the shell's crown). Therefore, the bending moments diagram, as well as the form of displacements, change, as in Figure 7. The $\eta$ values are also influenced by the component $r(\mathrm{~N})$ from Equation (12).

\section{The shell of the Shumal Bridge}

The analysed example of the Shumal Bridge object in Dubai, or more precisely in Ras Al Khajmah in the United Arab Emirates, ${ }^{[23]}$ is the largest in the world. The geometrical characteristics of the shell are as follows: span $L=32.39 \mathrm{~m}$, shell height $H=9.57 \mathrm{~m}$, and radius of curvature $R=29.68 \mathrm{~m}$ (and corner $R_{\mathrm{n}}=8.19 \mathrm{~m}$ ). The type of corrugated metal sheet is defined by its dimensions as UC $500 \times 237 \times 12[\mathrm{~mm}]$, which are marked in Figure $5 \mathrm{~b}$ (and in the paper) as UC $a \times f \times t$. During the construction and monitoring of the object, strain gauge measurements, as well as geodetic measurements were carried out in the points given in Figure 6. The results of the analyses presented in the paper relate to the construction phase, where $z_{\mathrm{g}}$ determines the thickness, as in Figure 5.

Figure 8 presents the diagrams of the radial displacements that were obtained from geodetic measurements for the characteristic five levels of the backfill, which were designated as A, B, ... E. In the facility, various backfill thicknesses on both sides were used, and their values are given in Table 2 - due to the twin system of the shell in the object. For this reason, there was a lack of symmetry in the deformation of the circumferential band of the shell, which was not observed in the object in Ostroda.

Figure 9 shows a comparison of the radial displacement results obtained from the geodetic measurements $r(\mathrm{uw})$ and from calculations using Formula (17), as $r$ (FDM). They refer to the diagrams of the bending moments that are related to the curvature change, as in Formula (14), 


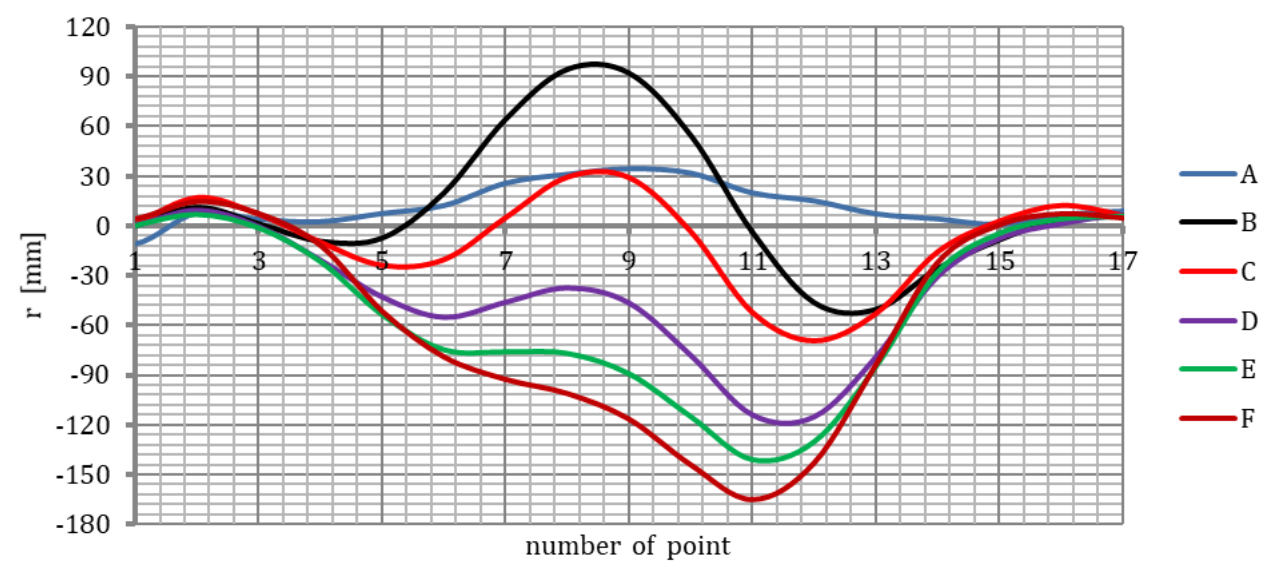

Figure 8: Functions of the deformations of the circumferential band of the shell.

Table 2: Comparison of the results of geodetic and strain gauge measurements.

\begin{tabular}{lllllll}
\hline Construction phase & A & B & C & D & E & F \\
\hline$\kappa(r) \bullet 10^{-3}[1 / \mathrm{m}]$ & 0.985 & 5.745 & 5.302 & 3.699 & 2.248 & 1.936 \\
$\kappa(\varepsilon) 10^{-3}[1 / \mathrm{m}]$ & 0.886 & 5.363 & 5.038 & 4.276 & 2.484 & 2.614 \\
$\eta$ & 0.899 & 0.933 & 0.950 & 1.156 & 1.105 & 1.350 \\
$w[\mathrm{~mm}]$ & 34.7 & 92.3 & 28.8 & -46.8 & -89.4 & -116.3 \\
$z_{g}[\mathrm{~m}]$ & $7.54 / 7.25$ & $9.78 / 9.99$ & $10.44 / 11.04$ & $10.48 / 11.32$ & $11.07 / 11.92$ & $11.73 / 12.32$ \\
\hline
\end{tabular}

when $E I=11.4 \mathrm{MNm}^{2}$, and the width of the band $a=0.5$ $\mathrm{m}$. Table 2 summarizes the values calculated from the comparison of curvature changes in the shell's crown. The displacement of the diagrams given in Figure 9 may be due to the horizontal displacements of the shell, which are a result of the lack of symmetry in soil interactions on the left and right of the shell.

\section{The deformation of the shell during the strengthening of the stone tunnel}

The design scheme of the shell of the reinforced stone tunnel in Jedlina is given in Figure 2. The shell has a shape of a half circle with $R=H=L / 2=3.5 \mathrm{~m}$. The profile of the corrugated metal sheet is of MP type with $200 \times 55 \times 5.5$ [ mm] - where MP $a \times f \times t$ (wave length, high, sheet thickness). Figure 2 presents the static scheme and results obtained from solving the arc using FEM.

In the study of the analysed object, changes in the shape of the shell during its strengthening were measured using terrestrial laser scanning ${ }^{[17]}$ and the Riegl VZ-400i device. The result of geodetic measurements were theradial displacement fields of the shell, which were processed into transverse profiles. Figure 10 shows one of the deflection profiles along the circumferential band of the shell. The parameter that determines the position of the analysed point on the arc is coordinate $s$, which is calculated along the circumference of the circle from the shell's crown ( $\mathrm{s}=$ $0)$. Positive values indicate the displacement of the shell into the object. In the displacement line, in the vicinity of the crown, the impact (weight) of the concrete mix being implemented from this area is visible.

The diagrams of the deflection and bending moments of the shell that are shown in Figure 10 significantly differ from the results obtained from the calculations of the object model when using FEM, as shown in Figure 3. For the calculation of the bending moments, as shown in Figure 10 , radial displacements $r(\mathrm{~s})$ and differential analysis, as given in Formula (1), were adopted. The constant bending stiffness $E I=103 \mathrm{kNm}^{2}$ of the circumferential band with a sheet width of $a=0.2 \mathrm{~m}$ was used. Therefore, in the object, the shell's support is not an articulated and non-sliding node. These reasons are the cause for the significant 

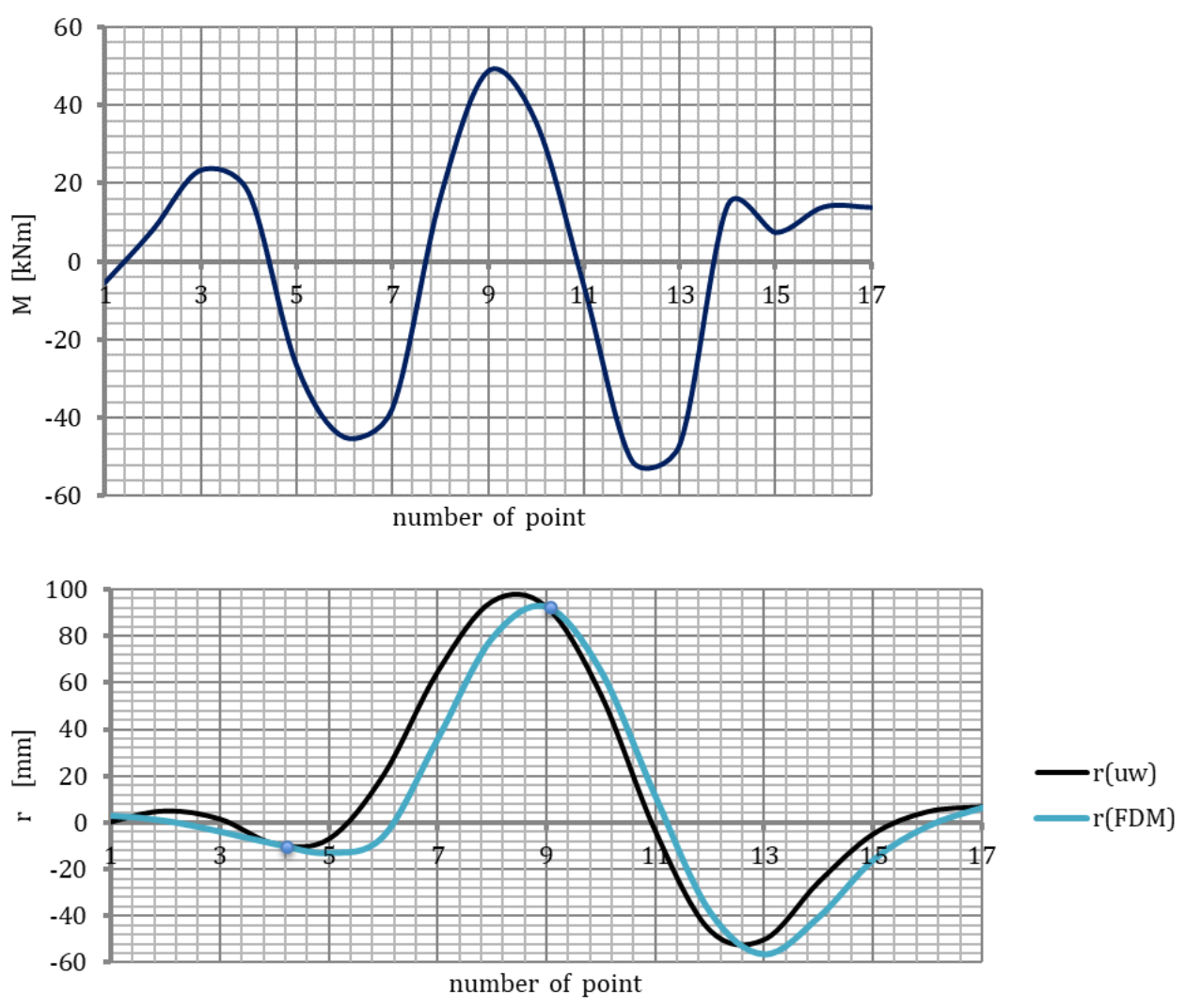

Figure 9: Radial displacements in the circumferential band of the shell during construction phase B.

discrepancies between the calculation results, obtained from FEM, and the values of measured displacements, such as the shell's deformations.

Figure 11 presents the results of the analysis of the impact of the mesh density of the FDM elements when adopting the algorithm given in Formula (17). Two collocation points were used in the calculations: one in the crown $(\mathrm{s}=0)$, and the other when $s=-3.5 \mathrm{~m}$. In this case, the curvature change was assumed based on the bending moments from Figure 10 and the relationship $\mathrm{k}=$ $M / E I$. Due to the fact that the moments were determined on the basis of displacements $r$ from Figure 10, full compliance of the diagrams is obtained with a dense mesh of the division into sections. Therefore, the differences of the diagrams that are visible in Figure 11 are only caused by the influence of the mesh and parameter $c$ that are given in the key of the diagram. The direct cause of the differences is the complex function of the curvature change. Therefore, when $\mathrm{k}(\mathrm{s})$ is a function with a complex waveform, it is necessary to use a dense measuring mesh. The case discussed in this point is a classic example where a collocation solution and FDM can be used.

\section{Summary}

In order to measure the internal forces in a shell's corrugated metal sheet, strain gauge measuring techniques are usually used. Due to significant displacements of the flaccid shell, geodetic measurements are also used. The displacement estimation algorithm that is discussed in the paper is based on the use of strain gauge (or fibre optic) measurements. It is intended for bar systems in which the design support conditions are not met. Collocation points in such a solution are used to consider the bar without constraints, but with specific changes in curvature, as the reference system. For this purpose, the transformation from the computational to the measuring system, that is, collocation points, is used. A small participation of axial forces in the displacements is beneficial for the algorithm.

Three examples of analysing the corrugated sheet shell are given in the paper. Good mapping of the deformation with the use of the collocation algorithm was indicated. In the case of a dense mesh and with a regular distribution of measuring points, it is convenient to use a differential approach. The analysed examples show a significant discrepancy between the support conditions 

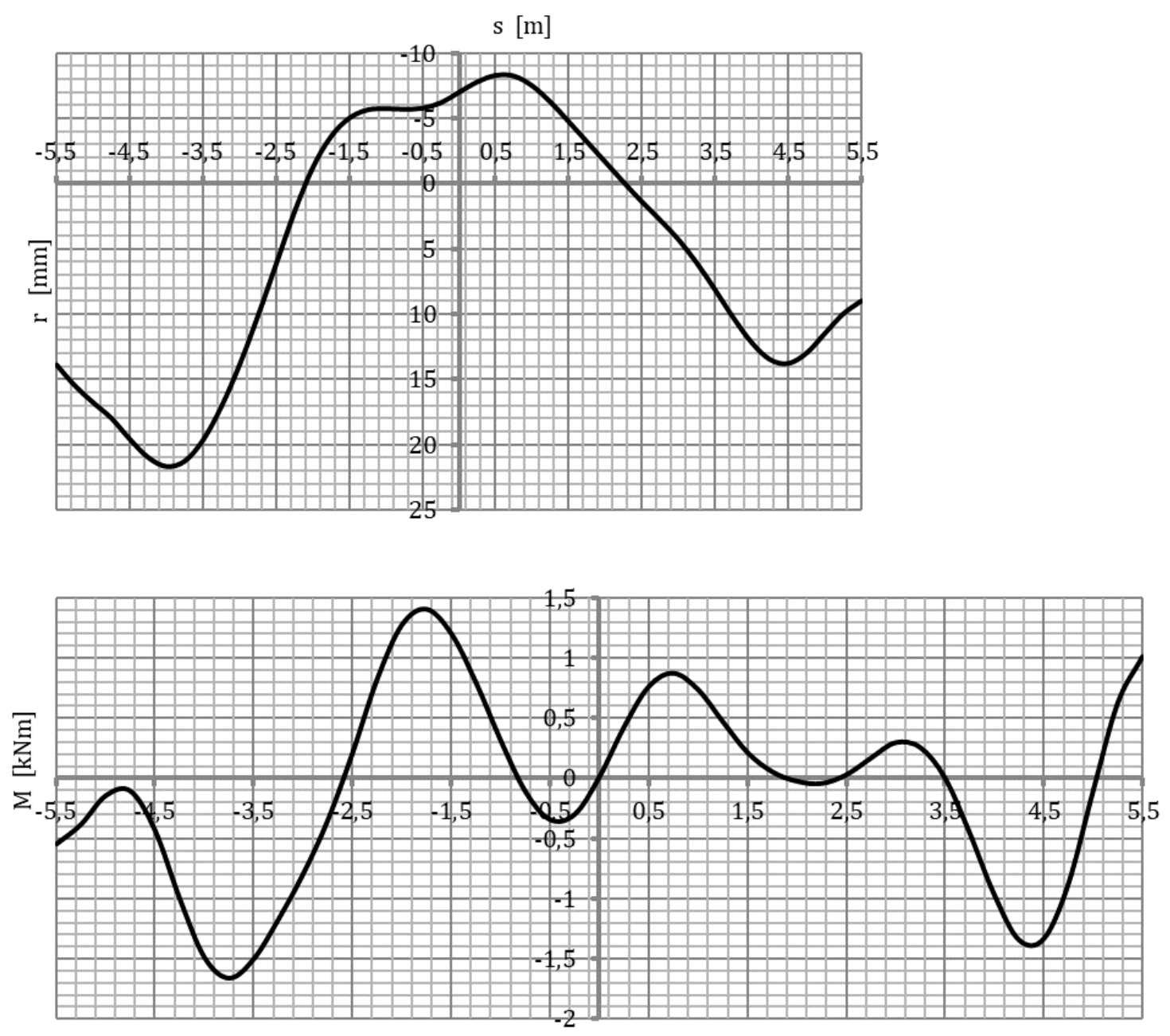

$s[\mathrm{~m}]$

Figure 10: Diagram of the displacements and bending moments of the shell in the radial direction.

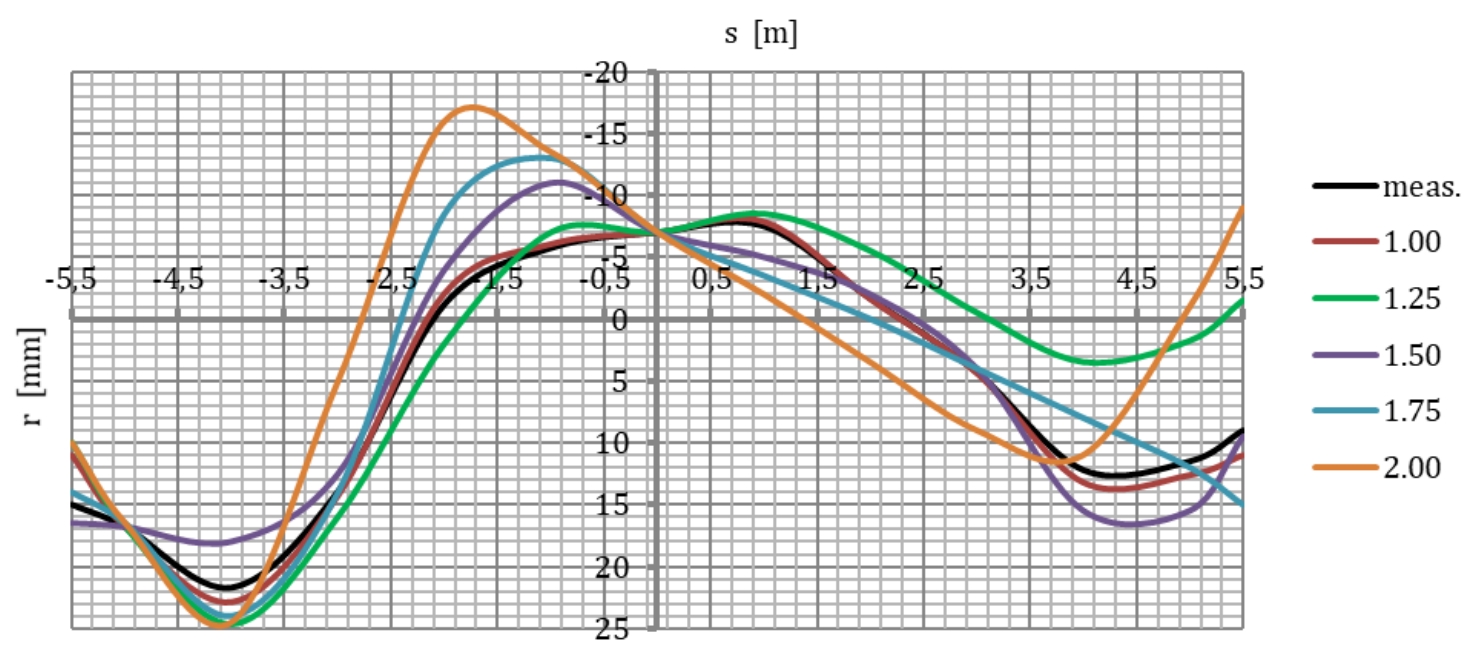

Figure 11: The diagram of displacements (curvature changes) in the circumferential bands of the shells. 
of the FEM calculation model and the actual static conditions in the object at the construction site. Such analyses are performed when monitoring an object during the laying of the backfill and the tracking of changes in the initial phase of construction. The deformation of the shell during the construction is a random phenomenon. Soil impact that results from its different levels on both sides of the shell, and also from the backfill compaction, is usually not symmetrical. Therefore, the function of soil interaction on the shell can be varied.

The presented calculation algorithm can be used in other models of structures, which are modelled as a bar system. The main advantage of the algorithm is the ability to analyse a selected fragment of the structure of the object, for example, one bar without taking into account the boundary conditions in its contact with the rest of the structure. The algorithm is sensitive to measurement errors. Therefore, when there are measurement inaccuracies, the results will not match - apart from in the case of the collocation points, and an unadjusted solution is then obtained.

\section{References}

[1] Ahmed M.R., Tran V.D.H., Meguid M.A. : On the role of geogrid reinforcement in reducing earth pressure on buried pipes: experimental and numerical investigations, Soils and Foundations, 55 (3) (2015) 588-599.

[2] Amir S., Ghannadpour M., Kiani P. : Nonlinear spectral collocation analiysis of imperfect functionally graded plates under end-shortening. Structural Engineering and Mechanics. Vol. 66, No 52018 pp. 557-568.

[3] Asp 0., Laaksonen A.: Instrumentation and FE-analysis of a large span culvert built under railway. Structural Engineering International, vol. 26, no 4/2016 pp. 357-364.

[4] Barbak P.M., Barbak P.P. : Metod sietok w zadaczach rasczeta stroitielnych konstrukcji. Stroizdat, Moskwa 1977.

[5] Bęben D.: Experimental study on the dynamic impacts of service train loads on corrugated steel plate culvert. Journal of Bridge Engineering ASCE, 18(4), (2014), 339-346.

[6] Bęben D.: Numerical analysis of soil-steel bridge structure. The Baltic Journal of Road and Bridge Engineering 4 (2009) pp. 13-21.

[7] Cecot W., Milewski S., Orkisz J. : Determination of Overhead Power Line Cabeles Configuration by FEM and Meshless FDM. International Journal of Computetional Methods. Vol. 15 No. 2 (2018).

[8] Łydżba D., Różański A., Sobótka M., Stefaniuk D., Chudy G., Wróblewski T.: Mechanical behaviour of soil-steel structure subjected to live load and different water conditions. Archives of Institute of Civil Engineering. (2017) 23, 163-174.

[9] Machelski C., Soil-steel structure shell displacements functions based on tensometric measurements. Studia Geotechnica et Mechanica, No 2 2018).
[10] Machelski C., Effects of surrounding earth on shell during construction of flexible bridge structure. Studia Geotechnica et Mechanica, No 2 2019)

[11] Machelski C.: Estimation the interaction effects of backfill on the shell in the soil-steel structure based on deformation of the shell. Przegląd Komunikacyjny 11/2016

[12] Machelski C., Janusz L.: Application of Results of Test in Developing 2D Model for Soil-Steel Railway Bridges. Journal of the Transportation Research Board. Solid Mechanic, 1 (2017), 70-75.

[13] Machelski C., Mońka M., Tomala P.: Monitoring of soil-steel structures during construction. Journal of Current Construction Issues 2/2019, 159-168.

[14] McVay M., Papadopoulos P. : Long term behavior of buried large-span culverts, Journal of Geotechnical Engineering, 112 (4) (1986), 424-442,

[15] Mellat, A. Anderson, L. Pettersson, Karuomi R.: Dynamic analysis of a short span soil-steel composite bridge for railways traffic using field measurements and numerical modelling. Engineering Structures, 69, 2014, 49-61.

[16] Milewski S. : Meshless Finite Difference Method with Higher Order Approximation-Applications in Mechanics. Arch. Comput. Methods Eng. (2012) $19: 1-49$

[17] Muszyński, Z., Rybak, J.: Evaluation of terrestrial laser scanner accuracy in the control of hydrotechnical structures. Studia Geotechnica et Mechanica, No 39(4), 2017, 45-57

[18] Orkisz J. : Finite Difference Method (part III). Handbook of Computetional Solid Mechanics 336-431. Springer-Verlag, 1998.

[19] Sobótka M. Numerical simulation of hysteretic live load effect in soil-steel bridge. Studia Geotechnika et Mechanica. (2014) 36.1. 103-109.

[20] Sobótka, M. (2020). Shape optimization of flexible soil-steel culverts taking non-stationary loads into account. Structures, 23, 612-620.

[21] Sobótka, M., \& Łydżba, D. (2019). Live load effect in soil-steel flexible culvert: role of apparent cohesion of backfill. European Journal of Environmental and Civil Engineering, 1-15.

[22] Sobótka, M., \& Machelski, C. (2016). Hysteretic live load effect in soil-steel structure. Engineering Transactions, 64(4), 493-499.

[23] Tomala P., Nowak M., Samolewski W., Szyszka M.: SoilSteel Composite Structure Monitoring During Bacfilling and Uncovering - Observations and Remarks. Conf. Transportation Research Board of Nationals Academies, Washington D.C., 12-15 January 2019.

[24] White T, Sargand S., Massada T.:, Evaluation of load rating procedure for metal culverts under shallow soil covers. Archives of Institute of Civil Engineering 23/2017, 311-323.

[25] Yu W.S., Li Z.L., Xie X.R., Guo L.Y. : Experimental study on earth pressure of corrugated steel culvert under high fill embankment, Applied Mechanics and Materials, 405-408 (2013) 1815-1819. 